\title{
Research of Electrosurgical Ablation with Antiadhesive Functionalization on Thermal and Histopathological Effects of Brain Tissues In Vivo
}

\author{
Wen-Tien Hsiao, ${ }^{1}$ Chun-Ming Kung, ${ }^{2,3,4}$ Jan-Show Chu, ${ }^{5}$ \\ Keng-Liang Ou, ${ }^{4,6,7,8}$ and Pei-Wen Peng' \\ ${ }^{1}$ School of Dentistry, Taipei Medical University, Taipei 110, Taiwan \\ ${ }^{2}$ Department of Dentistry, Cathay General Hospital, Taipei 106, Taiwan \\ ${ }^{3}$ Department of Dentistry, Cathay General Hospital, Sijhih, Taipei 221, Taiwan \\ ${ }^{4}$ Research Center for Biomedical Devices and Prototyping Production, Taipei Medical University, Taipei 110, Taiwan \\ ${ }^{5}$ Department of Pathology, School of Medicine, Taipei Medical University, Taipei 110, Taiwan \\ ${ }^{6}$ Graduate Institute of Biomedical Materials and Tissue Engineering, Taipei Medical University, No. 250, \\ Wu-Hsing Street, Taipei 110, Taiwan \\ ${ }^{7}$ Department of Dentistry, Taipei Medical University, Shuang Ho Hospital, Taipei 235, Taiwan \\ ${ }^{8}$ Research Center for Biomedical Implants and Microsurgery Devices, Taipei Medical University, Taipei 110, Taiwan \\ ${ }^{9}$ School of Dental Technology, Taipei Medical University, No. 250, Wu-Hsing Street, Taipei 110, Taiwan \\ Correspondence should be addressed to Keng-Liang Ou; klou@tmu.edu.tw and Pei-Wen Peng; apon@tmu.edu.tw
}

Received 27 February 2014; Revised 23 April 2014; Accepted 23 April 2014; Published 22 May 2014

Academic Editor: Joen-Rong Sheu

Copyright (C) 2014 Wen-Tien Hsiao et al. This is an open access article distributed under the Creative Commons Attribution License, which permits unrestricted use, distribution, and reproduction in any medium, provided the original work is properly cited.

\begin{abstract}
Thermal injury and tissue sticking are two major concerns in the electrosurgery. In the present study, the effect of lateral thermal injury caused by different electrosurgical electrodes on wound healing was investigated. An electrosurgical unit equipped with untreated (SS) and titanium oxide layer-coated $\left(\mathrm{TiO}_{2}\right.$-coated) stainless steel needle-type electrodes was used to create lesions on the rat brain tissue. $\mathrm{TiO}_{2}$ layers were produced by radiofrequency plasma and magnetron sputtering in the form of amorphous (TOSS-1), anatase (TO-SS-2), and rutile (TO-SS-3) phase. Animals were sacrificed for evaluations at 0, 2, 7, and 28 days postoperatively. TO-SS-3 electrodes generated lower levels of sticking tissue, and the thermographs showed that the recorded highest temperature in brain tissue from the TO-SS-3 electrode was significantly lower than in the SS electrode. The total injury area of brain tissue caused by TO-SS-1 and TO-SS-3 electrodes was significantly lower than that caused by SS electrodes at each time point. The results of the present study reveal that the plating of electrodes with a $\mathrm{TiO}_{2}$ film with rutile phases is an efficient method for improving the performance of electrosurgical units and should benefit wound healing.
\end{abstract}

\section{Introduction}

Electrosurgery has been widely accepted by physicians to aid in the removal of tumors since its original application by Bovie and Cushing in the 1920s. The basic components of a monopolar electrosurgery consist of the high-intensity radiofrequency $(\mathrm{RF})$ generator, the active electrode, the dispersive pad, and the patient. RF alternating current flows through tissue from an active electrode to a dispersive pad, resulting in tissue cutting, coagulation, and ablation [1].
RF tissue ablation makes thermal lesions and tissue coagulation around the tip of an active needle electrode. Although needle ablation has been widely applied to cardiology, urology, neurosurgery, and otolaryngology, there are still rare but occasionally serious complications that accompany the procedure [2]. The heat can destroy the targeted tumor in a range of $65-75^{\circ} \mathrm{C}$, and the temperatures above $75^{\circ} \mathrm{C}$ cause significant adjacent structures destruction [3]. Nontarget thermal damage to vital structures and tissue destruction adjacent to targeted lesions are the common complications 
from the needle ablation due to a rapid local temperature rise from the high current density. Carbonized charred tissue sticking to the electrode causes an abrupt drop in current density and eventually ceasing the operation [4]. Meanwhile, the sufficient lesion depth and diameter are difficult to obtain. To address these concerns, the RF ablation has incorporated different strategies to minimize the lateral spread of thermal energy and carbonized charred tissues, such as the automatic thermal monitoring system [5], the image-guide system [6], and the percutaneous saline-enhanced and impedancecontrolled system [7]. Recently, a relative simple method, the surface modification of the electrode, has been introduced to prevent lateral thermal damage and increase the precision of the lesion depth and diameter. Çeviker et al. [8] introduced the Teflon- (tetrafluoroethylene, PTFE-) coated electrode substrate to reduce the level of tissue sticking and charring. Simmons et al. [9] compared the gold- and platinum-coated electrodes on myocardial lesion size and suggested that deeper lesions should be able to be made when RF energy is delivered to a gold rather than platinum tip electrode. However, the optimal approach is still under development and an alternative coating material, titanium dioxide $\left(\mathrm{TiO}_{2}\right)$, has attempted to overcome the clinical drawbacks in the present study.

$\mathrm{TiO}_{2}$ was used in a wide range of technological applications due to its high refractive index, excellent transmittance, and photocatalytic property $[10,11]$. Recently, $\mathrm{TiO}_{2}$ has been reported to be good biocompatible and blood compatible. The $\mathrm{TiO}_{2}$ group is composed of three types of crustal structures, and especially the rutile and anatase phases have evolved as the model system in the surface coatings for biomedical materials [12]. Rutile and anatase phases have similar band-gap energies and they can be changed from insulator to a semiconductor by means of altering processing parameters [13].

The present study was directed toward quantification and comparison of the lesion position and thermal distribution produced by the monopolar RF energy application with different coatings. Specifically, the present study evaluated the effect of the various coatings of monopolar on the short-term histologic properties of brain tissue in an in vivo rat model.

\section{Materials and Methods}

2.1. $\mathrm{TiO}_{2}$ Thin Film Deposition and Property Evaluations. A deposition process that combined radiofrequency plasma and magnetron sputtering system equipped with one pure Ti target (99.99\% purity) was utilized to deposit the $\mathrm{TiO}_{2}$ film on commercial electrode (needle-type austenite AISI 304 stainless steel denoted as a SS electrode). All of the substrates were cleaned in an ultrasonic bath with a sequence of acetone and ethanol for $15 \mathrm{~min}$ followed by air drying before being loaded into the chamber. Subsequently, the chamber was evacuated at vacuum pressure $2.0 \times 10^{-6}$ torr for $15 \mathrm{~min}$ and then the substrates were presputtered by $\mathrm{Ar}^{+}$cleaning for $10 \mathrm{~min}$ to remove the native adsorbed contaminants and impurities under a radiofrequency power $225 \mathrm{~W}$ with chamber running pressure $8.0 \times 10^{-3}$ torr. After cleaning process, a mixture of $\mathrm{O}_{2} / \mathrm{Ar}$ with a fixed flow ratio (40/60) was introduced through mass flow controller to keep a working pressure of $8.0 \times 10^{-3}$ torr. Then, the substrate holder was heated and kept at $300^{\circ} \mathrm{C}$ during the following deposition. The untreated $\mathrm{Ti}$ was treated at a negative bias voltage of $200 \mathrm{~V}$ and the varying powers for $30 \mathrm{~min}$, creating a controlled $\mathrm{TiO}_{2}$ layer. For ease of identification, the SS electrodes coated with $\mathrm{TiO}_{2}$ layer at the amorphous, anatase, and rutile phases were labeled as TO-SS-1, TO-SS-2, and TO-SS-3 electrodes, respectively.

Raman spectra were recorded using the Horiba HR800 (Protrustech Co., Ltd., Taipei, Taiwan) with a $633 \mathrm{~nm}$ laser to detect the $\mathrm{TiO}_{2}$ phases. Topographical analyses were conducted using an atomic force microscope (AFM, DPN 5000, NanoInk, Skokie, IL, USA). The silicon nitride probe was scanned over a $1 \mu \mathrm{m} \times 1 \mu \mathrm{m}$ area in the tapping mode. The contact angles of the specimens were assessed by dropping $0.4 \mathrm{~mL}$ of distilled water on specimens and measured using a video-based goniometer (EA-01, Jeteazy Co., Ltd., Hsinchu, Taiwan). The specimens were tested 6 times to obtain average contact angle values.

\subsection{In Vivo Study}

2.2.1. Animal Models. RF-induced thermal lesion experiments were conducted in normal rat brain model. The animal procedures were approved and conducted by the Institutional Animal Care and Use Committee at Taipei Medical University (number LAC-99-0037). A total of 48 male SpragueDawley rats (weighing 276-300 g, BioLASCO Taiwan Co., Ltd., Taipei, Taiwan) were purchased and housed in cages for 14 days prior to experimentation. Food and water were available ad libitum. The animals were randomly allocated into 3 different experimental groups of 16 animals each.

2.2.2. Surgical Procedures. Aseptic precautions were utilized in all surgical procedures. The animals were positioned in a stereotactic frame under pentobarbital anaesthesia $(40 \mathrm{mg} / \mathrm{kg}$ IP). Bilateral cranial burr holes $(1 \mathrm{~mm})$ were drilled on the right and the left, at the coronal suture $4.0 \mathrm{~mm}$ lateral to the midline. Lesions were performed bilaterally using an ERBE ICC 300 RF generator (Elektromedizin $\mathrm{GmbH}$, Tübingen, Germany). A monopolar current at $20 \mathrm{~W}$ power setting was used and the duration of each penetration was $3 \mathrm{~s}$. Three $\mathrm{TiO}_{2}$-coated electrodes (TO-SS-1, TO-SS-2, and TO-SS-3) were evaluated and the regular SS electrode without any coatings was used as the control (SS). The $\mathrm{TiO}_{2}$-coated electrode was applied to one side and the SS electrode to the other. Performance of each electrode group was determined based on thermometry, tissue sticking, and histological examination.

2.2.3. Real-Time Thermometry and Quantification of Tissue Sticking. Real-time thermometry data was recorded from the initiation to completion of each lesion using a thermalimaging infrared camera with the thermal analysis simulation software (Advanced Thermo TVS-500EX, NEC Avio Technologies, Tokyo, Japan). The weight of each electrode was 
TABLE 1: Surface roughness, contact angle, and water drop profiles for $\mathrm{SS}$ and $\mathrm{TiO}_{2}$-coated electrodes.

\begin{tabular}{|c|c|c|c|c|}
\hline Description & $\mathrm{TiO}_{2}$ phase & Roughness (nm) & $\begin{array}{c}\text { Contact angle } \\
\text { (degree) }\end{array}$ & Water drop profiles \\
\hline SS & Untreated & $5.73 \pm 0.31$ & $70.3 \pm 1.4$ & \\
\hline TO-SS-1 & Amorphous & $2.41 \pm 0.37$ & $89.3 \pm 3.1$ & \\
\hline TO-SS-2 & Anatase & $2.52 \pm 0.21$ & $91.9 \pm 2.2$ & \\
\hline TO-SS-3 & Rutile & $3.44 \pm 0.27$ & $92.8 \pm 2.4$ & \\
\hline
\end{tabular}

measured before and after the operation. The degree of tissue sticking was calculated as the weight of sample after operation minus the weight of sample before operation.

\subsubsection{Injury Area and Histological Examination. Rats in each} group were sacrificed after $0,2,7$, and 28 days' recovery period $(n=4)$. Perfusion was done with $0.9 \%$ saline and then paraformaldehyde. Brains were taken and fixed in $10 \%$ buffered formalin and the samples covering lesions were cut from the brain specimens. They were treated in a graded alcohol series and embedded in paraffin. Continuous tissue sections $(3 \mu \mathrm{m})$ for all brain samples were taken for hematoxylin and eosin (H\&E, 3008-1\&3204-2, Muto, Japan). Stained samples were observed under a light microscope (BX51, Olympus, Japan). The total injury area in lesions for each group was quantified by the image software (SPOT basic software, SPOT imaging solutions, MI, USA).

2.3. Statistical Analysis. Statistical analyses were performed using the commercially available software program, SPSS 14.0 (Statistical Package for the Social Sciences, SPSS Inc., Chicago, IL, USA). For each experiment, data from 6 replicates were expressed as mean \pm standard deviation (SD) per variable, which were repeated to ensure validity. Analysis of variance (ANOVA) for comparison between groups was first performed and then Student-Newman-Keuls test was used in every other group. The statistical significance level was set at $P<0.05$.

\section{Result and Discussions}

Raman spectra of $\mathrm{TiO}_{2}$-coated electrodes are shown in Figure 1. No peaks were observed in the Raman spectra of the TO-SS-1 electrode. For the TO-SS-2 electrode, the Raman lines at $151,409,515$, and $633 \mathrm{~cm}^{-1}$ were assigned as the $E_{g}, B_{1 g}, A_{1 g}$ or $B_{1 g}$, and $E_{g}$ modes of the anatase phase, respectively, indicating that an anatase phase was formed in the SS electrode [14]. For the TO-SS-3 electrode, a band at $142.3 \mathrm{~cm}^{-1}$ was related to the long-range ordered structure of the crystalline rutile phase [15]. The $245.2 \mathrm{~cm}^{-1}$ mode is frequently observed in nanophase $\mathrm{TiO}_{2}$, whereas the mode at 442.2 is associated with the $\mathrm{E}_{\mathrm{g}}$ phase of the rutile phase, and $609.5 \mathrm{~cm}^{-1}$ is associated with the $\mathrm{A}_{1 \mathrm{~g}}$ modes of the rutile phase [16].

Figure 2 shows the surface morphologies of the SS and $\mathrm{TiO}_{2}$-coated electrodes using an AFM, which were acquired in a scanned range of $5 \times 5 \mu \mathrm{m}^{2}$. The SS electrode exhibited relatively planar surfaces with parallel polishing traces, as shown in Figure 2(a). The $\mathrm{TiO}_{2}$-coated electrodes exhibited similar topographies as shown in Figures 2(b) to 2(d), which exhibited the formation of a more uniform and denser $\mathrm{TiO}_{2}$ layer nanostructure with round grains. Table 1 lists the average surface roughness values. There was no difference between groups.

The contact angle of distilled water on SS and $\mathrm{TiO}_{2}-$ coated surfaces was examined, with results shown in Table 1. The SS surfaces had the lowest value $(70.3 \pm 1.4)$, whereas TO-SS-1 surfaces exhibited comparative hydrophobicity, with 


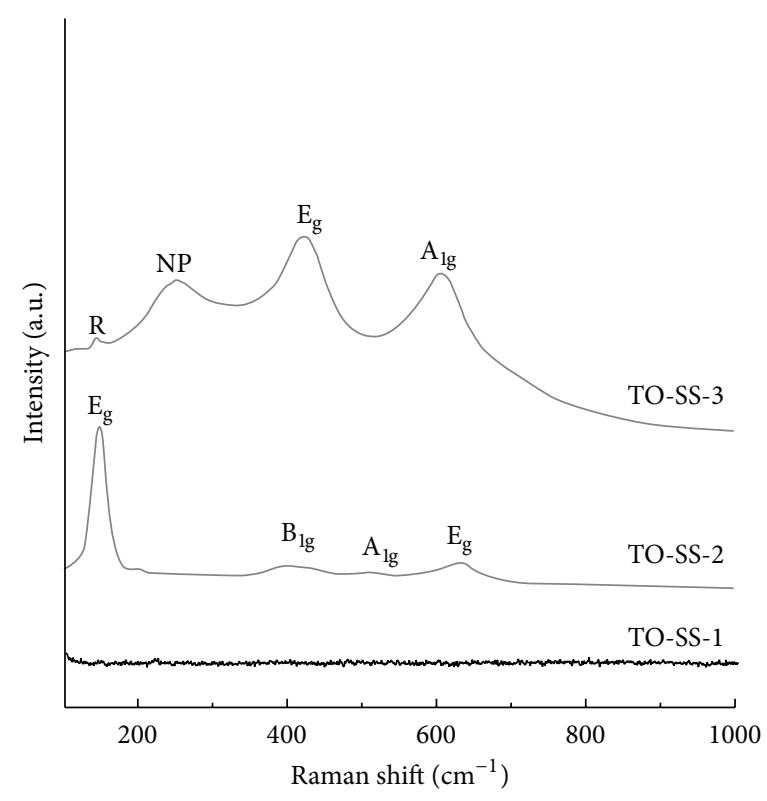

FIGURE 1: Raman spectrum of SS and $\mathrm{TiO}_{2}$-coated electrodes.

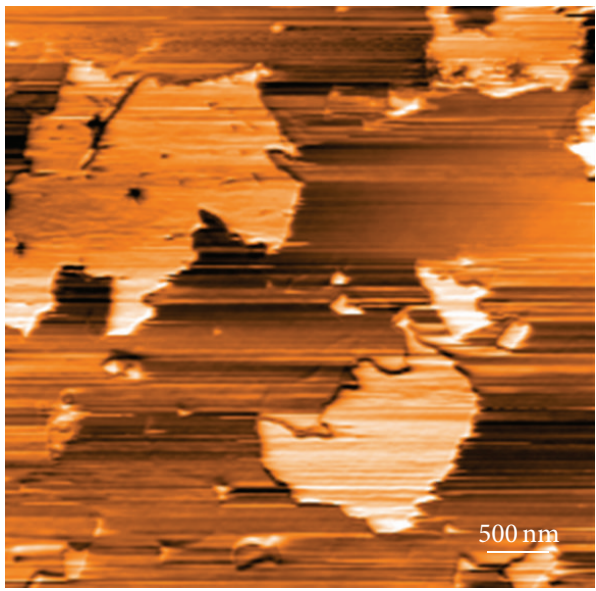

(a)

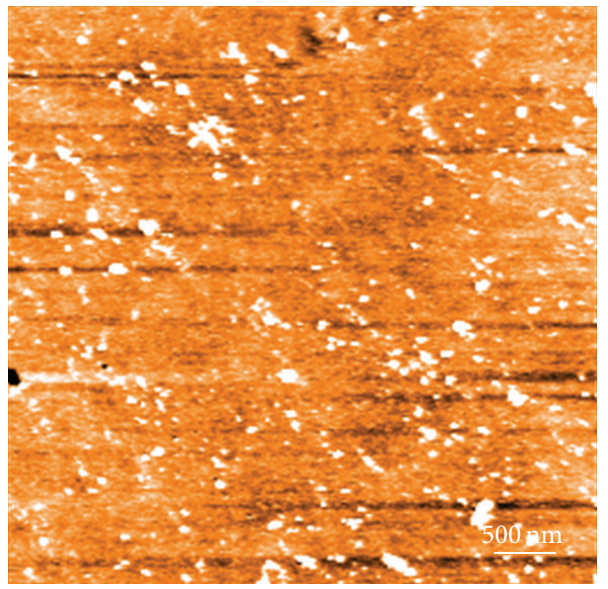

(c)

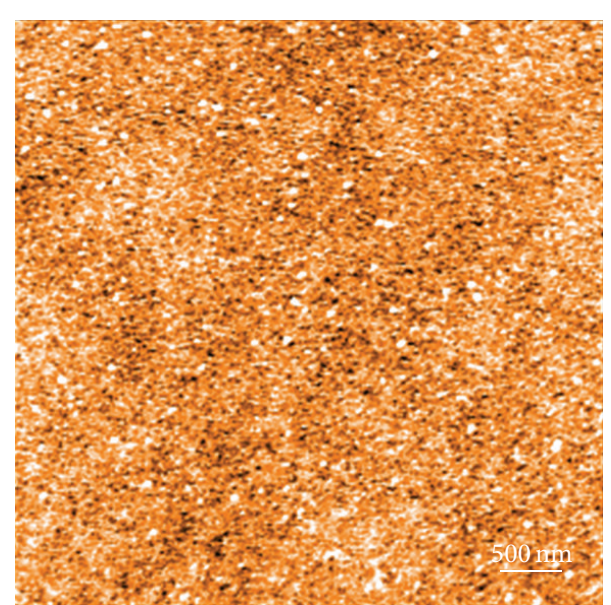

(b)

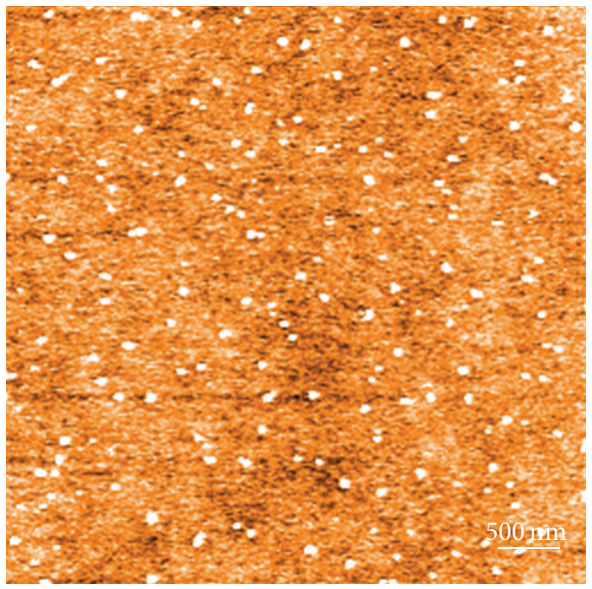

(d)

FIGURE 2: AFM tapping mode images (scan area $5 \mu \mathrm{m} \times 5 \mu \mathrm{m}$ ) of (a) SS, (b) TO-SS-1, (c) TO-SS-2, and (d) TO-SS-3 electrodes ((a, c) are 2D mode and (b, d) are 3D mode). 

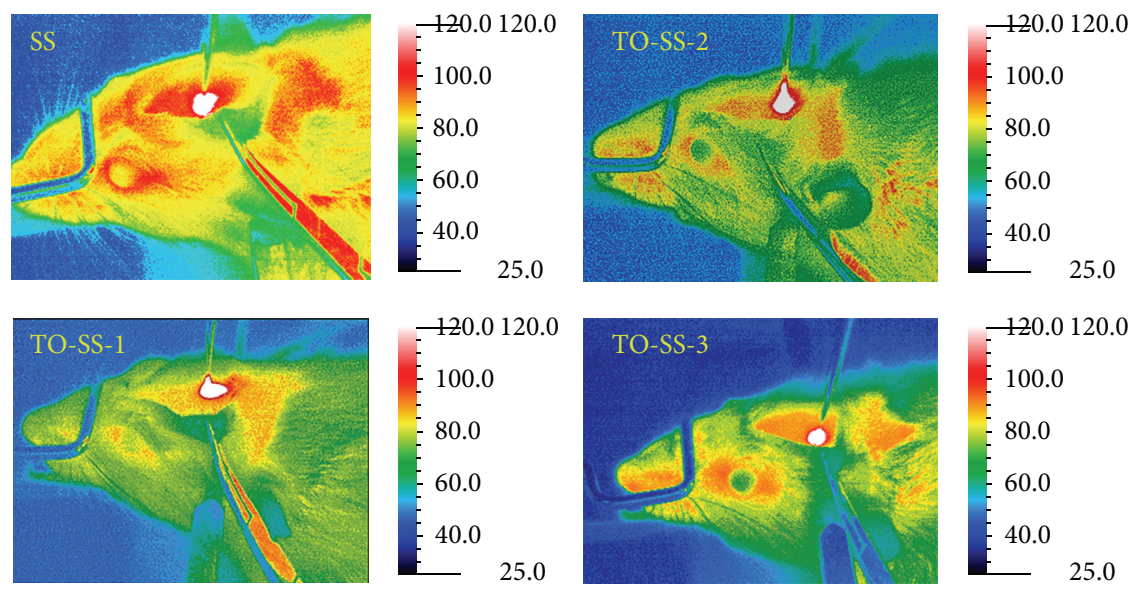

(a)

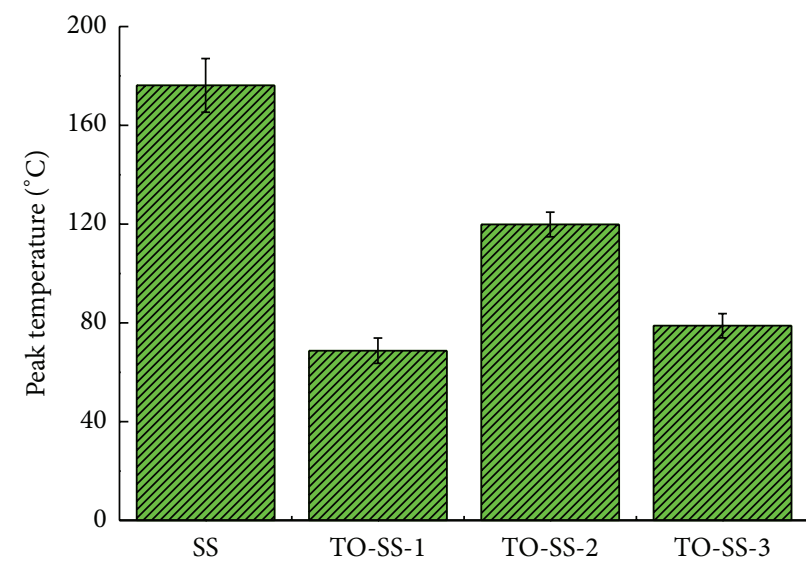

(b)

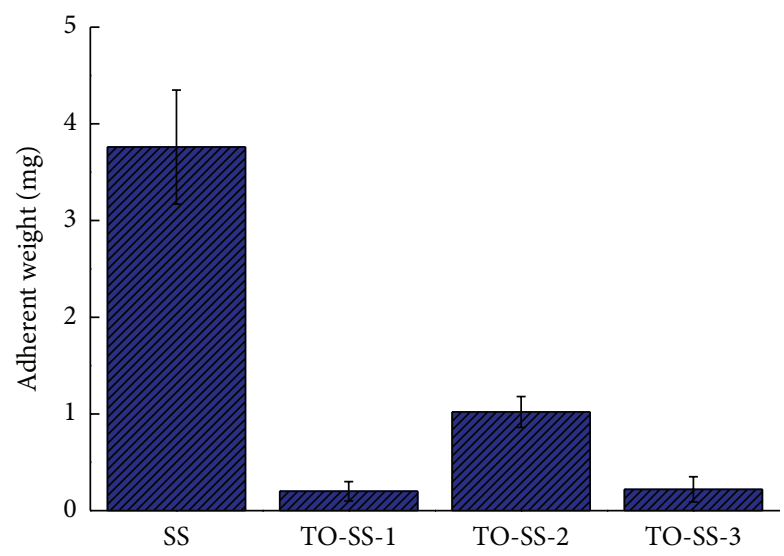

(c)

FIGURE 3: Comparisons of (a) thermographs, (b) the peak temperature, and (c) adherent weight for SS and $\mathrm{TiO}_{2}$-coated electrodes.

a value of $92.8 \pm 2.4$. One-way ANOVA revealed a significant difference between the $\mathrm{SS}$ and $\mathrm{TiO}_{2}$-coated electrodes $(P<$ 0.05). However, no significant difference between the $\mathrm{TiO}_{2}-$ coated electrodes was observed $(P>0.05)$.

The temperature distributions in ex vivo rat brain tissue around the $\mathrm{SS}$ and $\mathrm{TiO}_{2}$-coated electrodes measured using an infrared thermal imaging camera are shown in Figure 3(a).
A similar temperature distribution was found in experiments carried out with each needle type. Carbonization and tissue sticking occurred at the needle tips of each electrode, where the maximum temperatures were found in a concentric ring 3-5 $\mathrm{mm}$. The highest temperature recorded while applying a SS sample was $176.18 \pm 10.87^{\circ} \mathrm{C}$. The highest temperatures recorded for TO-SS-1, TO-SS-2, and TO-SS-3 electrodes were 


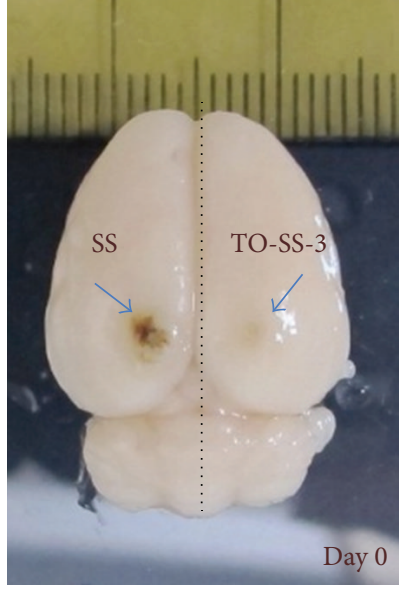

(a)

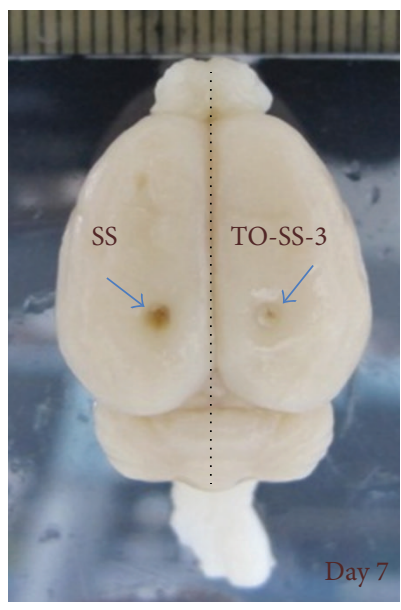

(c)

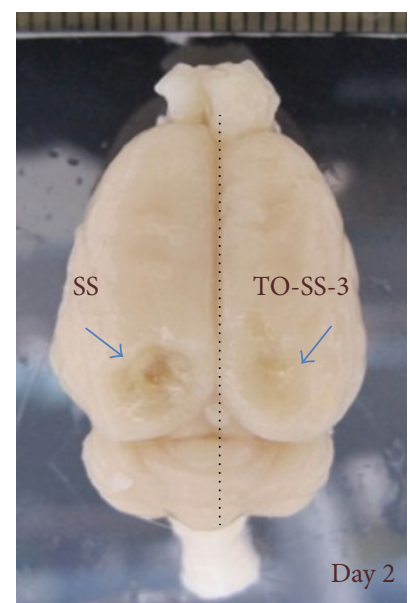

(b)

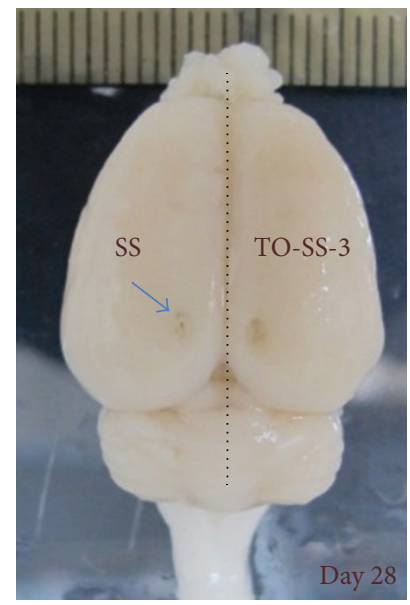

(d)

FIGURE 4: Gross observations showed the injury site created by SS (left) and TO-SS-3 (right) electrodes at (a) day 0, (b) day 2, (c) day 7, and (d) day 28 .

$68.73 \pm 5.12^{\circ} \mathrm{C}, 119.85 \pm 5.01^{\circ} \mathrm{C}$, and $78.83 \pm 4.92^{\circ} \mathrm{C}$, respectively, which were significantly lower than that in the SS group $(P<0.01)$ (Figure 3(b)). Electrodes were weighed before and after the operation for each group in order to measure the amount of tissue sticking to the needle tip (Figure 3(c)). The SS electrode needle tip showed a significantly higher amount of adhering tissue than the $\mathrm{TiO}_{2}$-coated electrode $(P<0.05)$. Among the $\mathrm{TiO}_{2}$-coated electrodes, the TO-SS-2 electrode exhibited the lowest amount of tissue adherent.

Pictures shown in Figure 4 reveal the difference in the total lesion areas caused by SS and TO-SS-3 electrodes. The injury created by the SS electrode was larger than that of the TO-SS-3 electrode as shown in Figure 4(a). The borders of the lesions sites for both electrodes were beginning to heal by the end of day 2, being both wider and shallower than immediately after the operation (Figure 4(b)). By day 7 the lesion areas were smaller for both the SS and TO-SS3 electrodes, and few blood cells remained (Figure 4(c)). By the end of day 28, the lesion created by TO-SS-3 electrodes was healed, and the small lesion site created by SS electrodes still remained as shown in Figure 4(d).
Histological examination of specimens for all electrode types showed varying amounts of coagulation necrosis and bleeding, indicating heat damage to the tissue as shown in Figure 5. When TO-SS-3 and TO-SS-1 electrodes were used, no obvious bleeding was detected postoperatively in treated tissues. In contrast, hemorrhaging caused by SS and TO-SS-2 electrodes was evident. At day 2, hemorrhaging in SS groups was markedly higher than in the other groups, and infections and apoptosis were observed at the treated site. The thermalinjury areas caused by SS electrodes were larger than those by the $\mathrm{TiO}_{2}$-treated electrodes, with the least tissue damage found when using the TO-SS-3 electrode. The thermal-injury areas tended to diminish for all groups at the end of day 7.

Commercially available electrosurgical electrodes are usually coated with Teflon to avoid tissue sticking. However, surgical smoke with an unfavorable flavor encouraged the advanced approaches. The objective of the present study was to establish an in vivo rat model to study the thermal effects on damage to brain tissue caused by electrosurgical ablation with $\mathrm{TiO}_{2}$-coated needle-type electrodes. 

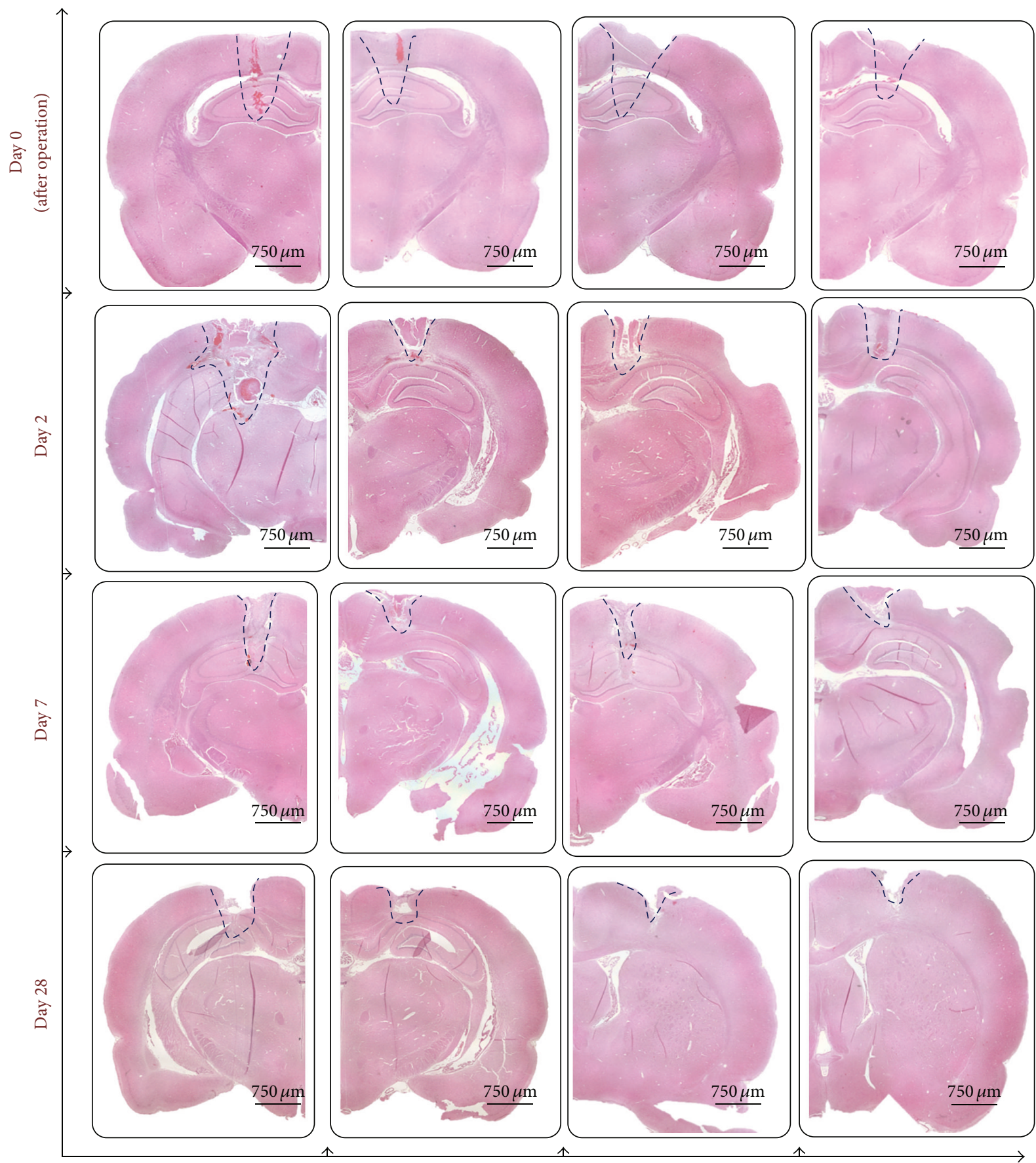

SS

TO-SS-1

TO-SS-2

TO-SS-3

FIGURE 5: Histological observation of injury area caused by SS and $\mathrm{TiO}_{2}$-coated electrodes at the end of day 0, day 2, day 7, and day 28.

It is well known that titanium possesses its excellent biocompatibility due to its very stable and corrosion resistant oxide layer $[17,18] . \mathrm{TiO}_{2}$ layers have been considered a promising coating for implants with proven biocompatibility and blood compatibility $[13,19]$. Therefore, coatings of $\mathrm{TiO}_{2}$ layers have been deposited on various devices via various technologies to increase clinical effectiveness. By means of radiofrequency plasma and magnetron sputtering, a layer of rutile, anatase, or amorphous phase $\mathrm{TiO}_{2}$ layer was deposited on commercially available electrodes.

Tissue thermographs showed that temperatures recorded for TO-SS-3 electrodes were significantly lower than those for SS electrodes under the same RF power setting. This can be attributed to the high electric and thermal conductivity of rutile phase $\mathrm{TiO}_{2}$ film [20]. Hence a TO-SS-3 electrode can deliver electrical energy to the target tissue more efficiently. 
This can prevent overheating of the electrode substrate and reduce the incidence of thermal injury. Macroscopic observation and histological examination showed clearly that TO-SS-3 electrodes produce a smaller area of injury than commercial SS electrodes.

\section{Conclusion}

A $\mathrm{TiO}_{2}$ film accompanied with hydrophobic surface can be formed and bonded on the needle-type electrode substrate via radiofrequency plasma and magnetron sputtering system. The enhanced thermal conductivity and surface hydrophobicity of $\mathrm{TiO}_{2}$ coatings with rutile phase can improve the performance of electrosurgical electrodes, in terms of tissue sticking and thermal injury. TO-SS-3 electrodes had lower levels of sticking tissue with lower surgical temperatures during electrosurgery. The total injury area of rats brain tissue treated with TO-SS-3 electrodes was significantly smaller than those of rat brain tissues treated with SS electrodes at all time points. This study reveals that the plating of $\mathrm{TiO}_{2}$ coatings on electrode substrates is a simple and effective means of improving the performance of electrosurgical units.

\section{Conflict of Interests}

The authors declare that there is no conflict of interests regarding the publication of this paper.

\section{Authors' Contribution}

Wen-Tien Hsiao and Chun Ming Kung contributed equally to this work.

\section{Acknowledgment}

This work was supported by a Grant from Taipei Medical University, under Grant no. TMU101-AE3-Y12.

\section{References}

[1] T. L. Smith and J. M. Smith, "Electrosurgery in otolaryngologyhead and neck surgery: principles, advances, and complications," The Laryngoscope, vol. 111, no. 5, pp. 769-780, 2001.

[2] H. Rhim, G. D. Dodd III, K. N. Chintapalli et al., "Radiofrequency thermal ablation of abdominal tumors: lessons learned from complications," Radiographics, vol. 24, no. 1, pp. 41-52, 2004.

[3] P. Hecht, K. Hayashi, A. J. Cooley et al., "The thermal effect of monopolar radiofrequency energy on the properties of joint capsule: an in vivo histologic study using a sheep model," The American Journal of Sports Medicine, vol. 26, no. 6, pp. 808-814, 1998.

[4] T. Lorentzen, "A cooled needle electrode for radiofrequency tissue ablation: thermodynamic aspects of improved performance compared with conventional needle design," Academic Radiology, vol. 3, pp. 556-563, 1996.

[5] H. Calkins, E. Prystowsky, M. Carlson, L. S. Klein, J. P. Saul, and P. Gillette, "Temperature monitoring during radiofrequency catheter ablation procedures using closed loop control. Atakr
Multicenter Investigators Group," Circulation, vol. 90, no. 3, pp. 1279-1286, 1994.

[6] S. Clasen and P. L. Pereira, "Magnetic resonance guidance for radiofrequency ablation of liver tumors," Journal of Magnetic Resonance Imaging, vol. 27, no. 2, pp. 421-433, 2008.

[7] J. Kettenbach, W. Köstler, E. Rücklinger et al., "Percutaneous saline-enhanced radiofrequency ablation of unresectable hepatic tumors: initial experience in 26 patients," The American Journal of Roentgenology, vol. 180, no. 6, pp. 1537-1545, 2003.

[8] N. Çeviker, S. Keskil, and K. Baykaner, "A new coated bipolar coagulator: technical note," Acta Neurochirurgica, vol. 140, no. 6, pp. 619-620, 1998.

[9] W. N. Simmons, S. Mackey, D. S. He, and F. I. Marcus, "Comparison of gold versus platinum electrodes on myocardial lesion size using radiofrequency energy," Pacing and Clinical Electrophysiology, vol. 19, pp. 398-402, 1996.

[10] J. C. Yu, W. Ho, J. Lin, H. Yip, and P. K. Wong, "Photocatalytic activity, antibacterial effect, and photoinduced hydrophilicity of $\mathrm{TiO}_{2}$ films coated on a stainless steel substrate," Environmental Science and Technology, vol. 37, no. 10, pp. 2296-2301, 2003.

[11] U. Diebold, "Structure and properties of $\mathrm{TiO}_{2}$ surfaces: a brief review," Applied Physics A, vol. 76, no. 5, pp. 681-687, 2003.

[12] Y. Liu and A. R. West, "Semiconductor-insulator transition in undoped rutile, $\mathrm{TiO}_{2}$, ceramics," Journal of the American Ceramic Society, vol. 96, pp. 218-222, 2013.

[13] M. F. Maitz, M.-T. Pham, E. Wieser, and I. Tsyganov, "Blood compatibility of titanium oxides with various crystal structure and element doping," Journal of Biomaterials Applications, vol. 17, no. 4, pp. 303-319, 2003.

[14] W. F. Zhang, Y. L. He, M. S. Zhang, Z. Yin, and Q. Chen, "Raman scattering study on anatase $\mathrm{TiO}_{2}$ nanocrystals," Journal of Physics D, vol. 33, no. 8, pp. 912-916, 2000.

[15] M. S. P. Francisco and V. R. Mastelaro, "Inhibition of the anatase-rutile phase transformation with addition of $\mathrm{CeO} 2$ to $\mathrm{CuO}-\mathrm{TiO}_{2}$ system: raman spectroscopy, $\mathrm{X}$-ray diffraction, and textural studies," Chemistry of Materials, vol. 14, no. 6, pp. 25142518, 2002.

[16] J. Zhang, M. Li, Z. Feng, J. Chen, and C. Li, "UV raman spectroscopic study on $\mathrm{TiO}_{2}$-I. phase transformation at the surface and in the bulk," Journal of Physical Chemistry B, vol. 110, no. 2, pp. 927-935, 2006.

[17] M. S. Wang, F. P. Lee, Y. D. Shen, C. H. Chen, K. L. Ou, and S. F. Ou, "Surface, biocompatible and hemocompatible properties of meta-amorphous titanium oxide film," International Journal of Applied Ceramic Technology, 2013.

[18] P. C.-H. Kuo, H.-H. Chou, Y.-H. Lin, P.-W. Peng, and K.-L. Ou, "Effects of surface functionalization on the nanostructure and biomechanical properties of binary titanium-niobium alloys," Journal of the Electrochemical Society, vol. 159, no. 5, pp. E103E107, 2012.

[19] Z. Yang, J. Wang, R. Luo et al., "Improved hemocompatibility guided by pulsed plasma tailoring the surface amino functionalities of $\mathrm{TiO}_{2}$ coating for covalent immobilization of heparin," Plasma Processes and Polymers, vol. 8, no. 9, pp. 850-858, 2011.

[20] H. Okubo, "Enhancement of electrical insulation performance in power equipment based on dielectric material properties," IEEE Transactions on Dielectrics and Electrical Insulation, vol. 19, pp. 733-754, 2012. 

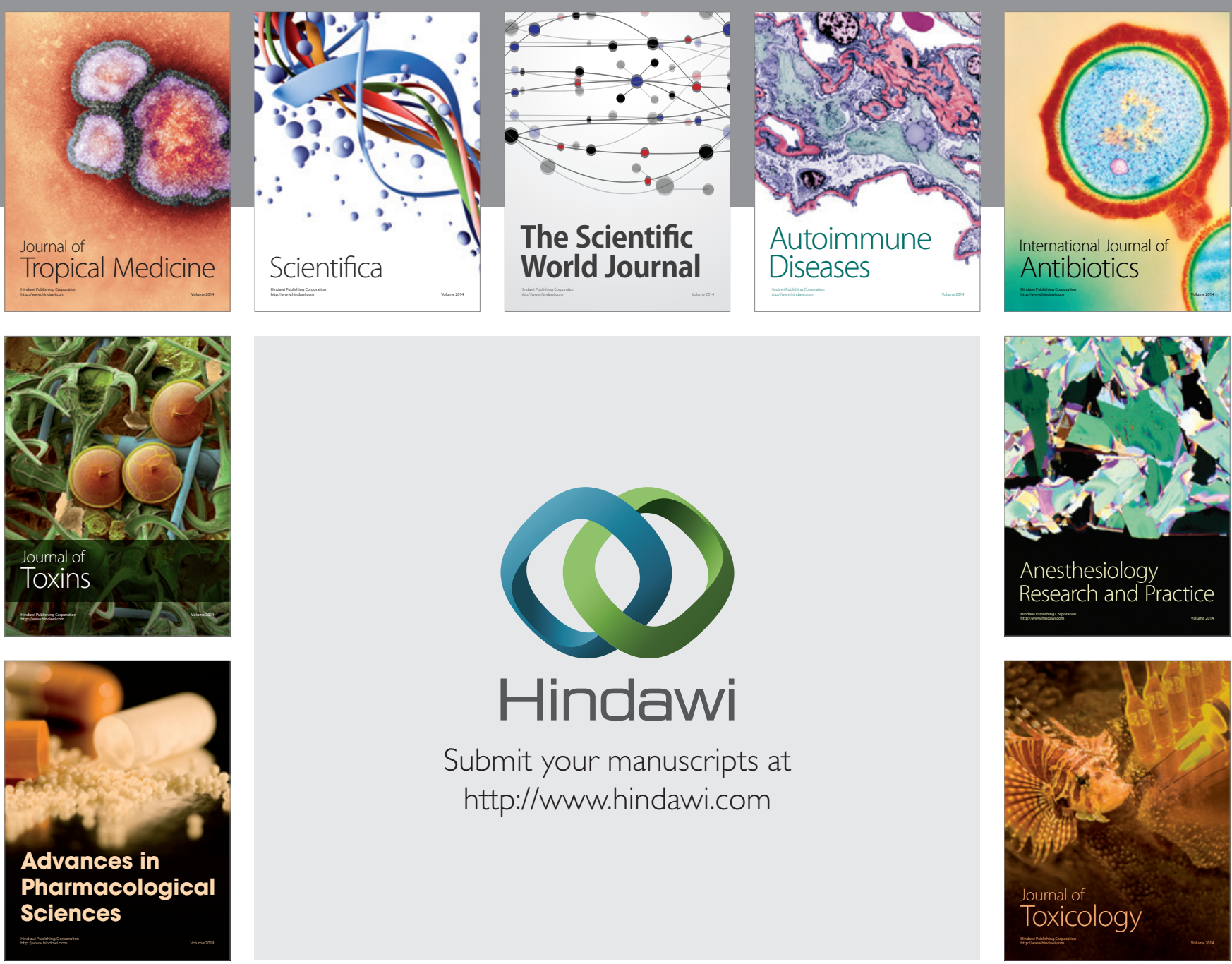

\section{Hindawi}

Submit your manuscripts at

http://www.hindawi.com
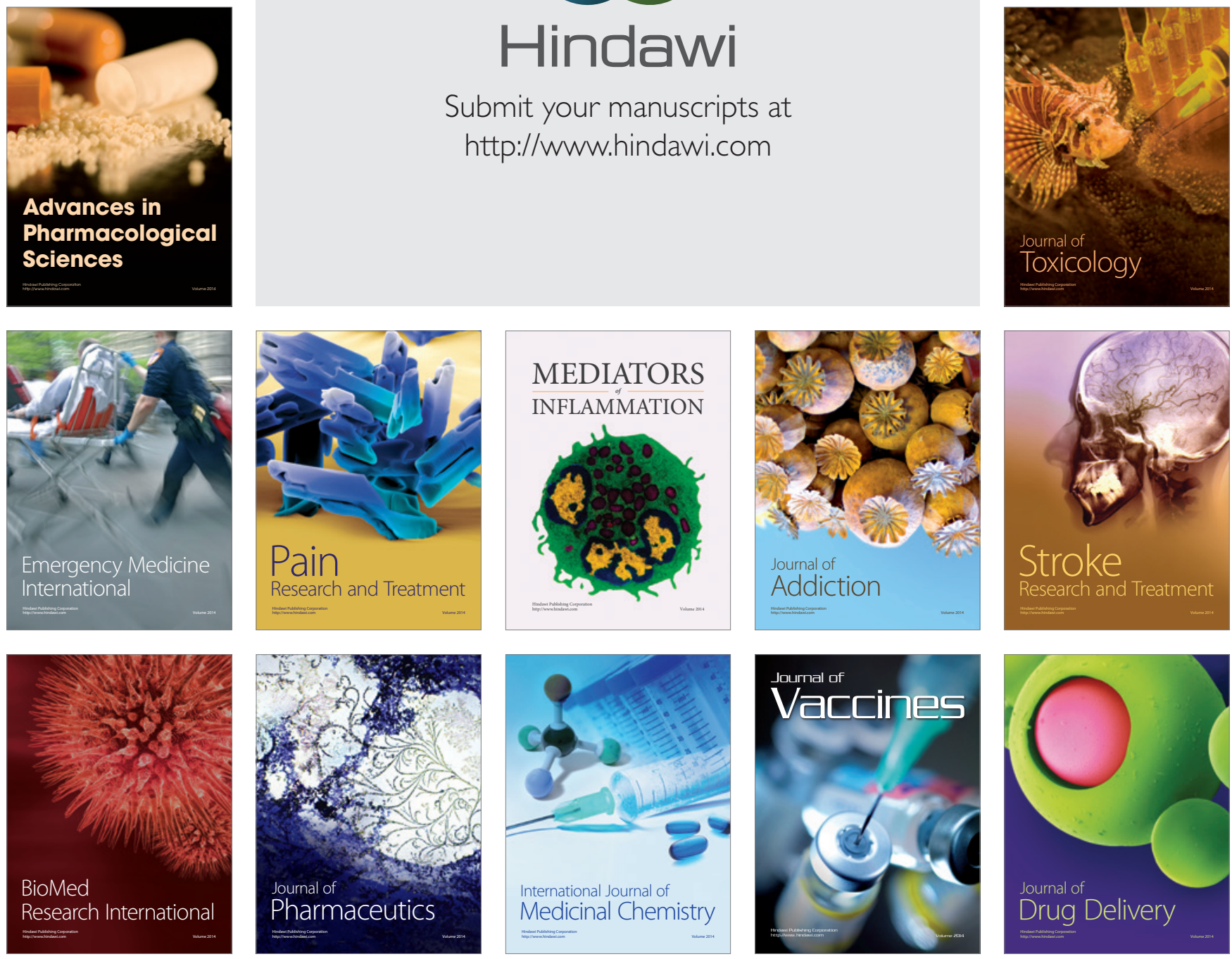